\title{
Alternância de código entre o português e o cantonês e construção de identidade no discurso de uma macaense
}

Lídia Maria dos Santos ${ }^{1}$

Resumo: Esse trabalho propõe-se a analisar, na sequência do contacto entre as línguas portuguesa e chinesa, durante mais de quatro séculos, em Macau, o uso do code-switching (CS) do português para o cantonês na interação espontânea entre quatro mulheres macaenses. Como arcabouço teórico, trabalhei com a sociolinguística interacional de forma a depreender funções pragmático-interativas para essa alternância de código. Consideramos aqui que o CS constitui uma das mais significativas marcas identitárias desta comunidade.

Palavras-chave: alternância de código; interação; línguas em contacto; identidade; macaenses.

\section{Apresentação}

Em Macau, China, ao longo de mais de quatro séculos, o cantonês e a língua portuguesa têm vindo a fazer, em graus diferentes, mas ininterruptamente, parte da vida quotidiana dos residentes, através de um longo e irregular processo de aquisição/aprendizagem motivado por força das interações interculturais, da necessidade de comunicação, das ideologias e da sobrevivência.

Como corolário da existência de mais de um código linguístico em determinadas sociedades, um fenómeno linguístico se apresenta: o uso alternado de línguas (doravante code-switching - CS) durante a interação social.

Esse fenómeno entre o cantonês e o português é amplamente observável em interações entre os macaenses ${ }^{2}$ em geral e entre estes e alguns chineses em particular. Trata-se de uma realidade linguística e social de que todos têm consciência e que todos os que vivem ou viveram em Macau conhecem.

1 Mestre pelo Departamento de Português da Universidade de Macau com a dissertação Alternância de código entre o português e o cantonês e construção de identidade no discurso de uma macaense, orientada pelo Professor Doutor Roberval Teixeira e Silva. O presente texto é parte deste nosso trabalho de pesquisa. Email: lidiarex123@gmail.com

${ }_{2}^{2}$ Não vamos aqui discutir o conceito de macaense que é uma questão antropologicamente complexa. Para isso, consultar Pinharanda Nunes neste volume; Costa (2004); Cabral e Lourenço (1993). Aqui, macaense será apenas considerado, nesse ambiente de mistura, aquele que é descendente de europeus, euroasiáticos e asiáticos e tem algum grau de domínio do português e também do cantonês.

26 fragmentum, N. 35, parte I. Laboratório Corpus: UFSM, Out./ Dez. 2012 
Para essa pesquisa, baseamo-nos no método etnográfico (ERICKSON, 1996) com o intuito de fazer a análise do discurso de uma macaense produzido em um diálogo espontâneo entre um grupo de amigas também macaenses. Trabalhamos com diferentes autores, especialmente com Gumperz (1982a ; 1982b) e Goffman (1959; 1967; 2002 [1979]), fundadores da Sociolinguística Interacional, que se dedicaram à análise do material linguístico como resultado e construção da interação social. Trabalhamos ainda com outros teóricos, como Grosjean (1982), Koziol (2000), Myers-Scotton (1993a), Auer (1984) e Oliveira (2006), que contribuíram com diferentes pontos de vista na descrição das funções do code-switching, sob uma perspectiva da língua em interação.

O CS é um fenómeno linguístico que merece ser estudado porque não é idiossincrático nem aleatório. É partilhado, em diferentes graus, pelos sujeitos que compõem uma comunidade de fala, independente do nível de escolaridade e de classe socioeconómica (apud OLIVEIRA, 2006, p. 55), e torna-se mais ou menos recorrente em função dos contextos.

Acreditamos que muitas pessoas que vivem ou que viveram em Macau formaram ideias erróneas sobre este fenómeno ao se depararem com esta realidade linguística. Da mesma forma, fizeram-no alguns linguistas como Haugen (1953; 1956) e Weinreich (1953) (apud OLIVEIRA, 2006, p. 48 e 58), quando se debruçaram sobre o estudo da interferência linguística no discurso bilingue, na década de 1950. Uma dessas ideias, por exemplo, era a de que os sujeitos recorrem ao CS por não dominarem plenamente nenhuma das duas línguas, o que os colocava socialmente na condição de cidadãos menos capazes cultural e linguisticamente. E quando as línguas envolvidas tinham uma relação politicamente hierarquizada, como é o caso do cantonês e do português durante o período ideologicamente colonial, a presença do CS no discurso era uma marca para o despoletar de um processo de segregação entre os sujeitos na comunidade (TEIXEIRA E SILVA; LIMA-HERNANDES, 2010).

No caso de Macau, evidentemente, fatores históricos, ideológicos, políticos e sociais concorreram e concorrem para determinar o prestígio social que apenas o português teve durante muitos anos. No entanto, a necessidade, enquanto fenómeno da sobrevivência, não deixa de exercer a sua força invencível, visto que comunicar é a atividade básica da vida das pessoas. Dessa forma, o cantonês impôs-se como língua de comunicação na vida quotidiana dos macaenses.

O rótulo negativo que há muito foi colocado nesse fenómeno linguístico típico da comunidade macaense não tem fundamento em nenhuma teoria cultural ou linguística. Pretendemos, assim, indicar que o code-switching entre o português e o cantonês deve ser reconhecido e aceite como um dos traços de identidade macaense, para além do patuá, dos poemas de Adé, das 
histórias de Henrique Senna Fernandes, dos contos de Leonel Barros, do minchi, do tacho e da água do Lilau .

\section{Code Switching}

O CS envolve um conjunto múltiplo de funções de uso, embora apenas se possam conhecer possíveis funções na análise das interações. Para diversos pesquisadores, o CS só aparece a um nível elevado de competência bilingue. Foram vários os autores que se debruçaram sobre as funções do CS, mas, aqui, vou apenas realçar o estudo de Blom e Gumperz (considerado como precursor do estudo do CS (2002 [1979], em perspectiva da linguagem em interação).

O estudo deles permitiu distinguir dois tipos de CS: o situacional e o metafórico. O primeiro envolve a mudança de código de acordo com as normas que governam a interação, por exemplo, passar de uma conversa formal para uma informal, de uma conversa de humor para uma séria ou ainda de uma conversa delicada ou melindrosa para uma mais coloquial e solidária. E o segundo ocorre quando a mudança tem lugar em função do assunto a ser tratado; por exemplo, quando um dos códigos é usado para assuntos familiares e o outro para assuntos de trabalho. É no estudo do CS metafórico que Blom e Gumperz trazem a sua mais rica contribuição.

Gumperz (1982a) distinguiu ainda o we-code e o they-code. O we-code corresponde à língua falada pelo grupo minoritário; é usado entre os sujeitos do mesmo grupo em atividades informais. O they-code corresponde à língua maioritária e funciona em situações formais e na relação com pessoas fora do grupo. $\mathrm{O}$ we-code marca a identidade do grupo em relação ao outro que é o they-code.

Relativamente às funções do CS, Gumperz assume que o CS é usado com algumas funções principais: (i) para fazer citações (é comum os bilingues reproduzirem o que foi dito por terceiros na língua em que ouviram); (ii) para especificar o interlocutor (nas interações em que um interagente não domina as duas línguas, o bilingue dirige-se aos primeiros na língua materna deles); (iii) para expressar emoções através de interjeições, de reiterações (com o objetivo de clarificar o que foi dito quando os monolingues tendem repetir a ideia por outras palavras); (iv) para qualificar a mensagem (isto é, acrescentar mais dados para servir de achega à informação dada); (v) para personalizar (marcar intimidade, proximidade, familiaridade); e (vi) também para objetivar (marcar distanciamento ou poder). Realcei as funções de Gumperz (1982a), no entanto, autores como Myers-Scotton (1993), Auer (1984), Grosjean (1982), Koziol (2000) e Renata Oliveira (2006) também contribuíram para o estudo das funções pragmáticas do CS, e todos eles trabalharam a partir de Gumperz. O fundamental a sublinhar é que as categorias utilizadas podem servir apenas 
como referência, não é possível esgotá-las. Procurar entender com que funções, em uma interação específica, se alternam de um determinada língua para a outra pode dar-nos pistas sobre traços da construção identitária dos sujeitos em interação.

\section{Metodologia}

O discurso que vamos analisar, da interagente Maria, proveio de uma interação espontânea entre quatro amigas de infância com idade por volta de 40 anos. As quatro participantes nasceram em Macau e tiveram formação em português desde tenra idade. Das quatro, uma é filha de pais macaenses, outra é filha de pais chineses, a terceira é filha de pai português e de mãe indiana e a Maria, filha de pai português e mãe chinesa. Das quatro, três fizeram o ensino universitário, uma em Macau, uma na China e outra em Portugal. Todas falam português, cantonês, inglês e algumas sabem um pouco de mandarim. Focalizaremos o CS do português para o cantonês.

Ao longo do diálogo, a Maria participou em 169 turnos, dos quais 83 foram falados em português, 37 em chinês e 31 tiveram alternância dos dois códigos linguísticos e casos diversos que incluem momentos inaudíveis, uso de palavras soltas em inglês, espanhol, patuá (maquista) e italiano. Desses 31 turnos com alternâncias, selecionamos 23 para análise. Esses 23 turnos analisados contêm alternâncias do português para o cantonês que ocorreram no meio e/ou no final da fala da Maria.

$\mathrm{Na}$ transcrição, os trechos em itálico codificam o discurso enunciado em português. A tipografia em negrito identifica o que foi falado em cantonês. $\mathrm{O}$ aspecto analisado está sublinhado.

\section{Análise}

Vamos observar no exemplo a ocorrência do CS num trecho do discurso da Maria.

As interlocutoras estavam a falar sobre a internet até que a Maria mudou de assunto e lembrou-se de comentar sobre a reação de duas amigas quando viram uma fotografia antiga das quatro participantes deste diálogo no mural do seu facebook. 


\section{Exemplo (linhas 58 - 67)}

\begin{tabular}{|l|l|}
\hline Maria & $\begin{array}{l}\text { É. Só que, é por preguicite do meu homem, o que é que ele fer? Ele pegou na } \\
\text { fotografia e tirou com a máquina fotográfica, não, com o telefone e depois fer. } \\
\text { aquela ligação ao computador, de modo que a fotografiaa saiu meiaaa } \\
\text { desfocada. Mas quando foi lançada no facebook, ah, como o pessoal } \\
\text { ficou contente! Olha, como é que ela se chama??? }\end{array}$ \\
\hline Ivone & Hmmm! \\
\hline Maria & $\begin{array}{l}\text { A Teresa comentou: "Há tanto tempo que não vejo essas meninas. Então a } \\
\text { Isabel até parece que sumiu". Ah, depois, como é que ela se chama? A } \\
\text { Luísa, Ainda se lembram dela? A irmã dela namorou com o } \\
\text { José! }\end{array}$ \\
\hline Ana & Lembro-me. A Luísa. \\
\hline
\end{tabular}

Reparemos que o exemplo traz uma narrativa toda contada em língua portuguesa. Entretanto, quando chega o momento da avaliação, a narradora faz o CS para o cantonês. O comentário feito em chinês, "ah, como o pessoal ficou contente!", traz uma série de marcas. Segundo as categorias levantadas por vários teóricos, sobressai aqui a função de personalização. Essa função, como já indicado, marca intimidade, proximidade, familiaridade e também está associada ao we-code.

Assim, vemos na frase essas marcas de intimidade, por exemplo, porque todas as interlocutoras sabem a quem se refere a palavra "pessoal". A Maria marca intimidade com as suas interlocutoras ao retomar uma vivência partilhada do tempo liceal e que, por isso, é do conhecimento de todas. Essa marca de intimidade traz também a marca de identidade do grupo, o we-code. A Maria serve-se ainda do CS para avaliar a alegria que ela acha que as amigas do facebook (que não se viam há mais de 20 anos) sentiram ao rever as amigas presentes na referida fotografia.

A função de identidade do grupo levantada por Gumperz (1982a) e Grosjean (1982) evidencia a solidariedade grupal que fica sublinhada pelos traços comuns que as ligam, sobretudo na língua, e enquanto grupo.

É interessante destacar ainda, dentro da perspectiva de Labov (1972) a função de uma avaliação na narrativa. Como Labov (1972) já adiantava, a avaliação pode ser o ponto da narrativa, a sua razão de ser e que, por isso está plena de conteúdo afetivo e sociocultural que marca a identidade de grupo e a intimidade.

Além da avaliação, temos ainda a familiaridade estabelecida pela frase "Ainda se lembram dela? A irmã dela namorou com o José!". O tom intimista do trecho "a irmã dela namorou com o José!" sublinha mais uma vez a familiaridade, a função de personalização na realização do CS. 
Dessa forma, fica sugerido que, no discurso dessa macaense, ao fazer o CS, o cantonês traz marcas expressivas de proximidade, de intimidade. A alternância parece querer criar uma atmosfera mais íntima.

Nos dados, a função de personalização no uso do CS só não aparece em 3 casos, que ocorrem por falta de tradução de três palavras. Em todos os outros, a mudança do português para o cantonês parece ser motivada por aquela função. O cantonês, assim, ganha no discurso da nossa interlocutora o status de língua do afeto.

\section{Palavras finais}

Através dos dados analisados, concluímos que o CS usado pela Maria é sobretudo para criar uma atmosfera mais íntima e mais pessoal com as suas interlocutoras, para marcar e enfatizar a identidade do grupo e para transmitir solidariedade. Verificámos, então, que o CS tinha essencialmente uma função pragmática. Muitas outras formas de personalização aparecem nos dados em geral. Assim, essa função interacional do CS está incorporada na fala da Maria quando ela passa do português para o cantonês para qualificar a mensagem, para a clarificar, para fazer uma avaliação, para mostrar emoção, para criar uma certa proximidade entre ela e as suas interlocutoras, para evidenciar a identidade geográfica/de grupo, para mostrar solidariedade e confidencialidade e também quando quer exercer algum efeito sobre a sua interlocutora (função perlocucionária).

Por fim, gostaríamos de tecer uma consideração sobre o we-code: a ideia é que ele constitui o cerne da noção de pertença a uma comunidade e da construção de uma identidade de grupo para o sujeito bilingue. Pensando em termos da língua portuguesa e do cantonês, na identidade macaense não parece ser possível determinar qual das línguas corresponde ao we-code ou ao they-code, qual é a língua de afeto do grupo e qual é a língua do outro. O que nos pareceu mais significativo é que, na verdade, parece que a mistura das duas línguas, o próprio code-switching, é que é o we-code macaense. Mas essa é uma motivação para uma futura pesquisa.

\section{Referências}

AUER, Peter. Bilingual Conversation. Amsterdam: John Benjamins, 1984. BLOM, Jan-Petter; GUMPERZ, John J. O significado social da estrutura lingüística: alternância de códigos na Noruega. In: RIBEIRO, B.; GARCEZ, P. (org). Sociolingüística interacional. Porto Alegre, RS: AGE, (2002 [1972]). CABRAL, João de Pina; LOURENÇO, Nelson. Em Terra de Tufões: Dinâmicas da Etnicidade Macaense. Macau: Instituto Cultural de Macau, 1993. 
COSTA, Francisco Lima da. Fronteiras da identidade. O caso dos macaenses em Portugal e em Macau. In: Sociologia, Problemas e Práticas. 2004.

ERICKSON, F. Ethnographic microanalysis. In: S. L. McKay and N. H. Hornberger, eds. Sociolinguistics and Language Teaching. Cambridge: Cambridge University Press, 1996.

GOFFMAN, E. Presentation of self in everyday life. New York: Anchor, 1959.

Anchor, 1967.

Interaction rituals: Essays on face-to-face behavior. Garden City: - Footing. In: RIBEIRO, B. T.; GARCEZ, P. M. (orgs.). Sociolingüística Interacional. 2. ed. rev. amp. São Paulo: Loyola, 2002. p.107-148, 2002 [1979].

GROSJEAN, François. Life with two languages: an introduction to bilingualism. Cambridge, MA: Harvard University Press, 1982.

GROSSO, M. J. dos Reis. O Discurso Metodológico do Ensino do Português em Macau a Falantes de Língua Materna Chinesa. Universidade de Macau: Macau, 2007.

GUMPERZ, John J. Discourse Strategies. Cambridge: Cambridge University Press, 1982a.

Press, 1982b.

Language and social identity. Cambridge: Cambridge University - Convenções de contextualização. In: RIBEIRO, Branca Telles; GARCEZ, Pedro M. Sociolinguística interacional. São Paulo: Loyola, 2002 [1982a].

KOZIOL, Jessica Marie. Code-switching between Spanish and English incontemporary American society. Monografia (Inglês e Língua Estrangeira). St. Mary's College of Maryland. Maryland, 2000.

LABOV, W. The transformation of experience in narrative syntax. In:

(Ed.), Language in the inner city: Studies in Black English Vernacular (p. 354-396). Philadelphia: University of Washington Press, 1972.

MYERS-SCOTTON, Carol. Social Motivations for Codeswitching: Evidence from Africa. Oxford: Oxford Clarendon Press, 1993.

OLIVEIRA, Renata Sobrino Porto de. Code-Switching: Perspectivas Multidisciplinares. Dissertação de Mestrado. Rio de Janeiro, RJ: Pontifícia Universidade Católica, 2006.

TEIXEIRA E SILVA, Roberval; LIMA-HERNANDES, Maria Célia. Ligas Urbanas: Atitudes Linguísticas na Trama Discursiva de Macaenses e Paulistas Caipiras. Revista de Cultura 35. Macau: Instituto Cultural, 2010.

32 fragmentum, N. 35, parte I. Laboratório Corpus: UFSM, Out./ Dez. 2012 